\title{
ENSINO DE GRAMÁTICA: DE UMAABORDAGEM FORMAL PARA UMAABORDAGEM FUNCIONAL NA DESCRIÇÃO DO SN
}

\section{Márcia Jerscelene Pereira Oliveira * Clemilton Lopes Pinheiro **}

Resumo: Neste trabalho, fazemos uma reflexão sobre as contribuições que as análises formal e funcional da Lingüística moderna podem dar ao ensino escolar de sintaxe, especificamente no que diz respeito à estrutura do Sintagma Nominal em Português.

Palavras-chave: Ensino de Português. Funcionalismo. Sintagma nominal. Sintaxe.

\section{Introdução}

Os estudos lingüísticos desenvolveram-se e continuam desenvolvendo-se em várias direções, sendo definidos por duas tendências que se opõem: o Formalismo e o Funcionalismo. A análise lingüística de base funcional enfoca a estrutura gramatical, relacionando-a ao uso que se faz da língua, ou seja, a estrutura é entendida como motivada pela situação comunicativa. Já a análise lingüística de base formal atribui autonomia à língua de forma que sua descrição se limita a aspectos essencialmente estruturais.

Neste trabalho, enfocamos a descrição da estrutura interna do Sintagma Nominal (SN). Apresentamos uma revisão de alguns estudos sobre a estrutura interna do ( $\mathrm{SN}$ ), em Língua Portuguesa, desenvolvidos sob o olhar teórico dessas duas tendências dos estudos

Bolsista de Iniciaşāo Científica - PIBIC/CNPq/FAIE/UFAL

- Professor da Faculdade de Letras (FALE) da Universidade Federal de Alagoas (UFAI). doutor em Linguística pela UNESP. 
lingüísticos modernos. Nosso objetivo é mostrar as diferenças entre a análise de base formal e a de base funcional e relacioná-las ao ensino de gramática na escola.

\section{Estudos sobre a estrutura interna do SN em Português}

\subsection{Gramática Tradicional}

São bastante difundidas e discutidas as críticas feitas à Gramática Tradicional (GT). Não é nosso objetivo retomá-las aqui. No que diz respeito à questão que estamos enfocando, queremos destacar como uma falha da GT a ausência da noção de Sintagma Nominal como uma categoria de análise no estudo da Sintaxe. Segundo Perini (1991, p. 37), a inexistência de uma noção clara de Sintagma Nominal obriga a gramática a descrever "o comportamento dessa classe de maneira desnecessariamente complicada e sem unidade - em outras palavras, de maneira não sistemática".

Para o autor, o estabelecimento da noção de sintagma nominal como uma classe de formas solucionaria duas grandes deficiências da análise sintática tradicional: a falta de generalização e a de explicação da estrutura propriamente dita. Ao explicitar os possíveis núcleos de um objeto direto, por exemplo, a GT repete a mesma lista de possibilidades do núcleo de um sujeito, de um objeto indireto ou de um adjunto adnominal, ou seja, ela deixa escapar uma generalização importante da língua: a "de que a mesma classe de formas (o sintagma nominal) pode aparecer em todas essas funçōes sintáticas" (PERINI, 1991, p. 38). Da mesma forma, não se pode entender como descrição da estrutura do sujeito, por exemplo, apenas a apresentação da lista de possibilidades de seu núcleo.

Seguindo esse raciocínio, Perini (1995) afirma que, no estudo na estrutura interna do SN em Português, é preciso abandonar praticamente toda a análise tradicional. Segundo o autor, em um sintagma como "aqueles seus livros de psicologia", a GT 
distingue apenas duas funções: o núcleo (livros), e os adjuntos adnominais (aqueles, seus, de psicologia). Essa análise é simples demais para dar conta da complexidade dos fatos. As várias possibilidades de posicionamento de cada um dos termos é um exemplo dessa complexidade. Um tem posição fixa no sintagma, como "aqueles", que só pode aparecer em primeira posição; outro, como "de psicologia", embora também tenha posição fixa, não é a mesma de "aqueles; já "seus" apresenta possibilidade de transposição, embora limitada.

Essa análise admite um número maior de funções dentro do $\mathrm{SN}$, além das duas previstas pela análise tradicional (núcleo e adjuntos). Perini (1995) propõe outras funções, pois, se os três "adjuntos adnominais" apresentam posições diferentes, devem ter também funções diferentes. A seguir, apresentaremos com algum detalhe a descrição do $\mathrm{SN}$ proposta por esse autor, como um exemplo de análise formal.

\subsection{Abordagem Formalista}

Perini (1995) afirma que o sintagma nominal pode ser definido de maneira muito simples: é o sintagma que pode ser sujeito de alguma oração. Nos exemplos a seguir, "professor" (01) é um SN, porque é sujeito da oração; "um neurótico" (02) é também um SN porque, embora não seja sujeito em (01), pode ser sujeito em outra oração, como em (02). Já a expressão "em São Paulo" não é um sintagma nominal, pois não poderia ser nunca sujeito de alguma oração.
(01) Esse professor é um neurótico
(02) Um neurótico rabiscou meu livro.
(03) Em São Paulo chove bastante. 
A análise do $\mathrm{SN}$ é feita com base $\mathrm{em}$ traços de natureza posicional, já que, segundo o autor, "uma análise dos termos do SN em termos de posição é suficiente para revelar muitos dos grandes traços da estrutura" (1995, p. 94). O ponto de partida é o SN máximo, ou seja, aquele em que todas as posições possíveis são preenchidas por itens léxicos'.

O SN é dividido em duas porções: a área esquerda, composta pelos elementos que precedem o núcleo, e a área direita, composta pelo núcleo mais os elementos que o seguem. O estudo dos diversos itens que podem ocorrer na área esquerda do $\mathrm{SN}$ mostra uma surpreendente variedade de posicionamentos possíveis e, portanto, de funções distintas. A área esquerda compreende seis posições fixas e quatro posições variáveis. As posições fixas definem seis funções, denominadas (na ordem em que ocorrem no sintagma) determinante (Det), possessivo (Poss), reforço (Ref), quantificador (Qf), pré-núcleo externo (PNE) e pré-núcleo interno (PNI). As posiçōes variáveis ocorrem nos intervalos entre as posições fixas, exceto entre dois prénúcleos, onde não pode ocorrer nenhum item. O esquema completo da área esquerda é o seguinte (as posiçōes variáveis são identificadas como PV): [Det PV4 Poss PV3 Ref PV2 Qf PVI PNE PNI].

Cada posição define, portanto, uma função. O Det ocupa a primeira posição, o Poss, a segunda, o Ref, a terceira, e assim por diante. Por exemplo, "Aquele" em "aquele meu computador" exerce função de determinante, porque ocupa a primcira posição. No entanto, as quatro posições variáveis definem uma única funçāo, a de numerador (NUM). Isso se deve ao fato de que os mesmos itens léxicos ocorrem nessas quatro posiçōes, sendo as versões resultantes totalmente correspondentes. Há, portanto, dez posiçōes, mas apenas sete funções na área esquerda.

Para o autor, o SN máximo nāo passa de uma abstraçâo, já que nāo ocorre na prática. Um SN máximo realizado seria tão longo e sobrecarregado que acabaria sendo rejeitado pelos falantes, por razōes que nada têm a ver com a sintaxe. Porém, Perini afirma que, apesar de abstrato, o SN máximo é necessário como ponto de referência para a análise. 
Por razões tanto sintáticas quanto semânticas, certos itens da área esquerda năo podem co-ocorrer no mesmo sintagma com outros itens que desempenham a mesma função (a menos que esta seja de numerador), como mostra o exemplo (04) em que ocorrem dois determinantes: "o" e "aquele".

(04) *o aquele sapato.

Quanto à área direita do $\mathrm{SN}$, a descrição é feita da seguinte forma. Distinguem-se três funções: núcleo (NSN), modificador interno (ModI) e modificador externo (ModE). Em "um ataque cardíaco fulminante", por exemplo, "ataque" é o NSN; "cardíaco", o ModI; e "fulminante", o ModE. A necessidade de propor dois modificadores se explica pelo fato de que sua ordenação é fixa:

Apesar de a estrutura da área direita ser mais simples do que a da esquerda, a análise, na prática, é mais difícil, pois, na área direita há um alto grau de polivalência dos itens envolvidos. As dúvidas de análise na área direita são também muito mais freqüentes do que na área esquerda, porque a maioria das funções na área esquerda são ocupadas por itens especializados: "nosso", por excmplo, só pode ser Poss, "aquele" só pode ser Det e assim por diante. Às vezes, é necessário, na análise da área direita, o estudo de cada caso em particular.

Não pretendemos nos estender nos detalhes da descrição do SN tal como desenvolvida por Perini (1995). Pretendemos, com essa breve explanação apenas mostrar as bases para a explicação da constituição interna do SN. O autor descreve como se estrutura um SN em Português, explicando as restrições de ocorrências dos itens. Essa explicação é baseada principalmente na posição que os itens assumem no sintagma e, secundariamente, nos traços semânticos dos próprios itens. Trata-se, portanto, de uma análise estritamente formal. Todo e qualquer fato relativo a aspectos 
pragmáticos é excluído da análise, como é possível depreender da seguinte afirmação de Perini (1995, p. 96) acerca da definição de SN máximo: "um SN máximo realizado seria tão longo e sobrecarregado que acabaria sendo rejeitado pelos falantes, por razōes que nada têm a ver com a sintaxe."

\subsection{Abordagem Funcionalista}

Um exemplo de análise da estrutura interna do $\mathrm{SN}$ de base funcional é a realizada por Liberato (2001). A autora parte da hipótese de que a forma do SN é parcialmente determinada por sua função referencial. Considerando que as formas lingüísticas se ajustam às necessidades comunicativas do falante, são definidas seis funções semânticas no SN, com base na sua contribuição para os processos de delimitação (tarefa do falante/escritor) e identificação (tarefa do ouvinte/leitor) do referente. Dessa forma, ela tenta mostrar de que maneira aspectos pragmáticos, sintáticos e semânticos se integram na gramática. As funções semânticas no SN são identificadas como classificador, subclassificador, qualificador, recortador e quantificador.

Toda descrição, mais ou menos detalhada, começa com uma classe mais ampla que vai sendo restringida na medida do necessário. O item que representa essa classe mais ampla em que o referente é enquadrado numa determinada descrição é chamado de classificador. Em um exemplo como $(05)^{2}$, o SN "a prova” pode ser usado para alguém se referir a uma entidade enquadrada na classe de entidades que se costuma chamar "provas". Mas, há situações em que a descrição desse referente requer maior nível de detalhamento. Imaginemos um contexto em que no mesmo dia foram realizadas duas provas, uma de matemática e outra de português. Nesse caso, seria necessária mais informação para que o referente possa ser

Os exemplos empregados nesta seção são os mesmos de Liberato (2001). 
identificado, como no exemplo (06), em que uma subclasse é delimitada dentro da classe "provas".

(05) A prova foi muito difícil.

(06) A prova de matemática foi muito difícil.

Liberato explica que, dependendo das informações disponíveis no contexto, a descrição do referente pretendido pode envolver uma hierarquia complexa de subclasses que vão sendo expressas no SN, motivando assim a sua constituição interna. A descrição será tão detalhada quanto o falante/escritor ache necessário para a identificação adequada do referente pretendido.

A função subclassificadora delimita uma subclasse mais ampla em que o referente é enquadrado na descrição e que engloba outras subclasses possíveis no contexto, ou seja, apresenta uma função restritiva. Já o qualificador fornece características do referente que, no entanto, não são utilizadas como delimitação de subclasse de uma classe mais ampla em que o referente é enquadrado na descrição. Exerce apenas uma função explicativa. Essas funçōes, como destaca Liberato (2001, p. 57), são necessárias “à descrição de vários aspectos da ordem interna do SN".

No exemplo (07), os sintagmas preposicionados $\mathrm{T} \sim \mathrm{em}$ função restritiva: "de notas" delimita um subconjunto de "cadernos de notas", "de aparelhos mecânicos" delimita um subconjunto de "projetos", e "de Verrochio" delimita um subconjunto de "estúdios". Já em (08), "dos séculos XVIII e XIX” qualifica as peças do antiquário, mas não as diferencia como um subconjunto. Todas as peças do antiquário são dos séculos XVIII e XIX. O sintagma preposionado exerce função apenas explicativa. 
(07) Os cadernos de notas de Leonardo estão repletos de projetos de aparelhos mecânicos, muitos dos quais ele não deve ter visto no estúdio de Verrochio...

(08) Para quem pensa que as antiguidades brasileiras resumem-se aos móveis coloniais, vale a pena conferir o antiquário Resplendor. Suas peças, dos séculos XVIII e XIX, incluem não apenas móveis de diversos estilos, como também arte sacra e prataria.

As descrições semânticas do SN (classificador, subclassificador, qualificador, recortador e quantificador) são, portanto, manifestadas pelos constituintes do SN, como adjetivos, sintagmas preposicionado, artigos, numerais, e apresentam todas uma motivação pragmática: o processo de identificação/delimitação do referente. É nesse sentido que essa análise pode ser enquadrada no paradigma teórico funcionalista, no sentido em que é colocado por Neves (1997, p. 16): "Na verdade, a gramática funcional tem sempre em consideração o uso das expressões lingüísticas na interação verbal, o que pressupõe uma pragmatização do componente sintáticosemântico do modelo lingüístico.”

\section{Contribuições para o ensino}

A finalidade do ensino de Língua Portuguesa, de acordo com as propostas curriculares nacionais, é desenvolver o domínio ativo do discurso nas diversas situações comunicativas, ou seja, o aluno deve freqüentar as aulas de Português para desenvolver sua competência discursiva.

Um dos aspectos da competência discursiva é o sujeito ser capaz de utilizar a língua de modo variado, para produzir diferentes efeitos de sentido e adequar o texto a diferentes situaçōes de interlocução oral e escrita. É o que se chama de competência lingüística e estilística. Isso, por um lado, coloca cm evidência as virtualidades das línguas humanas: o fato de que 
são instrumento flexíveis que permitem referir o mundo de diferentes formas e perspectiva; por outro lado, adverte contra uma concepção de língua como sistema homogêneo, dominado ativa e passivamente pela comunidade que o utiliza (PCNs, 1998, p. 23).

Como vimos, a gramática tradicional não responde a esta finalidade. Além de lidar com regras e conceitos incoerentes e contraditórios, recai numa simples exposição de taxonomia. No que diz respeito à questão aqui tratada, a estrutura do $\mathrm{SN}$, nem a mera taxonomia é realizada, já que, como também já mostramos, a noção de sintagma nominal sequer é prevista pela GT.

Uma abordagem formal do SN, tal como proposta por Perini (1995), permite o reconhecimento das estruturas da língua. Temos aí um avanço em relação ao ensino tradicional. Considerando essa descrição, o estudo do SN, em sala de aula, pode ser feito a partir de exercícios estruturais, de oposição e similaridade, por exemplo.

Os fenômenos de similaridade permitem exercícios de substituição em que os elementos substituídos conservam a mesma posição e a mesma função na estrutura da frase. No caso específico do fenômeno discutido no âmbito deste trabalho, na estrutura do SN. Por exemplo, no sintagma "A menina", o determinante "a" pode ser substituído por "aquela, uma, esta, minha", e outros itens, sem haver mudança da função de determinante. A oposição estrutural, por sua vez, sugere exercícios de transformação em que se operam elementos gramaticais de valores diferentes, isto é, dado um SN como modelo, é possível estabelecer uma mudança gramatical, conforme se observa nos exemplos:

(09) O aluno estudioso

(10) O aluno que estuda (o adjetivo transforma-se em oração) 
Esse tipo de ensino avança em relação ao ensino tradicional, no sentido de que contribui para a noção de que o uso e os fatos devem prevalecer sobre os preconceitos normativistas e sobretudo para a noção de que a língua é um saber interior, pessoal, dos falantes, de onde o ensino deve partir e em que deve, sempre, se basear. No entanto, como envolve apenas habilidades de domínio da estrutura formal da língua para a produção ou reconhecimento de frases gramaticalmente corretas, e, como nem sempre são consideradas as condições de produção do enunciado, esse tipo de ensino acaba, em última análise, não contribuindo para o desenvolvimento da competência discursiva dos estudantes.

Além disso, falta, nesse tipo de atividade estrutural, o procedimento reflexivo, que, segundo Neves (2003, p. 115), leva o trabalho com uma gramática teoricamente sustentada no uso lingüístico.

Privilegiar a reflexão é exatamente a razão de preconizar-se um tratamento da gramática que vise ao uso lingüístico. Não apenas o estudioso da língua portuguesa, mas também o falante comum, conduzido na reflexão sobre o uso da linguagem, vai poder orientar-se para a utilização eficiente dos recursos do processamento discursivo, e, a partir daí, chegar a uma sistematização dos fatos da língua legitimada pelo efetivo funcionamento da linguagem.

Considerando essa perspectiva de Neves (2003) e os próprios objetivos do ensino de Português, conforme os documentos oficiais, é a análise de base funcional que mais condições oferece para um ensino eficiente de gramática nas escolas. Segundo Oliveira e Coelho (2003), nos documentos governamentais para o ensino do Brasil, elaborados a partir da LDB 9.394/96, os objetivos gerais de Língua Portuguesa no ensino fundamental e médio são claramente correlacionados à perspectiva funcionalista de tratamento lingüístico. Os pontos gramaticais, por exemplo, devem ser tratados nas situações 
de produção, revisão e reescritura de textos, pautadas no uso lingüístico efetivo, portanto.

As questões relativas à morfologia e à sintaxe deixam de representar um fim em si mesmas para se constituírem em pontos cuja análise será necessária ao alcance do competente e eficiente desempenho lingüístico. Trata-se da proposta da gramática no discurso, do reconhecimento dos recursos gramaticais como componentes concorrentes da tessitura textual (OLIVEIRA E COELHO, 2003, p. 94).

Assim, nas atividades de análise lingüística, no que diz respeito especificamente à estrutura do $\mathrm{SN}$, é imprescindível partir do uso, para mostrar que a estrutura interna de um SN, bem como as relações entre seus constituintes têm motivação no discurso. Naturalmente, não cabe mais a análise descontextualizada e restrita ao nível da oração.

Seguindo a sugestão de tratar os aspectos gramaticais em atividades de revisão de textos, exemplificamos uma análise do $\mathrm{SN}$ possível de ser realizada em sala de aula. No trecho ${ }^{3}$ a seguir, dois SNs podem ser tomados para discussão em termos de sua estrutura interna: "o homem" e "o desemprego". É interessante demonstrar o que diferencia os dois SNs, apesar de apresentarem a mesma estrutura interna (artigo + substantivo). Enquanto o sintagma "o homem" é perfeitamente adequado no texto, porque o leitor facilmente identificará seu referente (a classe geral da espécie humana), o sintagma "o desemprego" não apresenta essa qualidade. Como não houve um processo de delimitação do referente "emprego", por meio de outros constituintes do SN, há uma ruptura entre o primeiro e o segundo parágrafo. O leitor, naturalmente, deve se perguntar "de que desemprego se está

Trecho de redação escolar, retirado de Costa Val (1999). 
falando?", "o que isso tem a ver com o meio social, a igualdade entre os homens?". Isso leva, entre outras questōes, ao fato de que o SN não está estruturado de forma adequada, a ponto de proporcionar a construção do sentido pretendido.

O homem como fruto do meio

O homem é produto do meio social em que vive. Somos todos iguais e não nascemos com o destino traçado para fazer o bem ou o mau.

O desemprego pode ser considerado a principal causa de tanta violência. A falta de condições do indivíduo em alimentar a si próprio e a sua família. (...)

A análise da estrutura do $\mathrm{SN}$ pode ser também correlacionada à atividade de compreensão leitora. Apontamos como sugestão desse tipo de atividade algo na linha do que faz Pinheiro (2003) com o SN "o mostrengo", no trecho $(12)^{4}$. O autor defende que a reiteração do referente "Sistema Seae-SDE-Cade" pelo SN "o monstrengo" realiza um movimento de articulação textual. Além disso, prevalece a avaliação que o produtor do texto faz em relação ao que ele está dizendo. Ao reiterar assim o referente, o produtor do texto deixa transparecer sua posição em relação ao sistema, ou seja, trata-se de algo que, na sua avaliação, não é bom.

A atividade de análise deve se centrar, portanto, na motivação pragmática da constituição do SN. O emprego do artigo definido se justifica pelo fato de que o referente já é conhecido, está sendo apenas

O trecho é um exemplo utilizado pelo próprio autor. 
retomado. Já o substantivo com valor axiológico se justifica pela intenção do produtor do texto. Enfim, uma série de possibilidades de tipos de SN poderia ser empregada para retomar o referente "Sistema Seae-SDE-Cade", mas a forma empregada foi a que, no momento da construção do texto, serviu aos propósitos comunicativos do autor.

No Brasil, complicado sistema Seae-SDE-Cade (Secretaria de Acompanhamento Econômico do MF, Secretaria de Direito Econômico do Ministério MJ, e Cade) foi montado a pretexto de "defesa da concorrência". Mas o que fez foi encobrir uma estapafúrdia combinação de objetivos de controle de preços e de intimidação das empresas privadas. No clima "antibusiness" da administração brasileira, infiltrada de petistas, a soma de poderes dados ao Cade equivale à doação de um revólver a lunáticos de asilo...

O monstrengo tem poderes para meter o bedelho em "aumentos injustificados de preços "ou "imposição de preços excessivos". Numa economia de mercado, quem julga os preços é o consumidor, e o único instrumento eficaz a respeito é a concorrência. E "preços excessivos" são criados pelo governo, via inflação.

As duas atividades de análise lingüística na perspectiva funcional apresentadas aqui exploram apenas os aspectos condicionados pela função referencial do $\mathrm{SN}$, os quais motivam sua constituição interna. É claro que há outros aspectos que apresentam outra motivação, muitos dos quais ainda pouco explorados pelas investigações lingüísticas. 


\section{Considerações finais}

Neste trabalho, retomamos a discussão sobre o ensino escolar de gramática. Associamos o ensino de gramática com o ensino de descrição lingüística, conforme proposto nos PCNs. Defendemos, em conformidade com os documentos oficiais que delineiam o ensino no Brasil, que a descrição lingüística não pode ser desvinculada do uso e deve ser ensinada com o objetivo de desenvolver a competência comunicativa dos alunos. Esse objetivo pode ser atingido se o ensino de gramática for pautado no modelo teórico funcionalista, pois esse modelo possibilita que a descrição do funcionamento da língua seja aliada ao seu uso e feita a partir das diversas manifestações textuais.

Centramos a discussão em um aspecto gramatical: a estrutura interna do Sintagma Nominal. Procuramos mostrar algumas possibilidades de habilidades lingüísticas que podem ser desenvolvidas a partir de um ensino de descrição do SN sob as perspectivas formal e funcional de análise lingüística. Na análise lingüística de base funcional, é imprescindível partir do uso, para mostrar que a estrutura interna de um SN, bem como as relações entre seus constituintes, têm motivação no discurso. Assim, não cabe a análise descontextualizada e restrita ao nível da oração.

\section{Referências}

COSTA VAL, M. da G. Redação e textualidade. São Paulo: Martins Fontes, 1999.

LIBERATO, Y. G. A estrutura interna do SN em Português. In: DECAT, M. B. N. et al. (orgs). Aspectos da Gramática do Português: uma abordagem funcionalista. Campinas/SP: Mercado de Letras, 2001. 
NEVES, M. H. de M. A Gramática Funcional. São Paulo: Martins Fontes, 1997.

- Que gramática estudar na escola? - Norma e uso na Língua Portuguesa. São Paulo: Contexto, 2003.

OLIVEIRA, M. R. de; COELHO, V. W. Lingüística funcional aplicada ao ensino de português. In: FURTADO DA CUNHA, M. A.; OLIVEIRA, M. R. de; MARTELOTTA, M. E. (orgs). Lingiiística funcional: teoria e prática. Rio de Janeiro: DP\&A, 2003.

PCNs - Parâmetros Curriculares Nacionais. Língua Portuguesa. Brasília: MEC/ SEF, 1998.

PERINI, M. A. Para uma nova gramática do Português. São Paulo: Ática, 1991.

. Gramática descritiva do Português. São Paulo: Ática, 1995.

PINHEIRO, C. L. Integração de fatos formulativos e interacionais na construção do texto: um estudo sobre o uso de formas referenciais na organização tópica. Linguagem em discurso, vol 4, no 1, 2003. 